\title{
Impact of postoperative complications on survival outcomes in patients with gastric cancer: exploratory analysis of a randomized controlled JCOG1001 trial
}

\author{
Masanori Tokunaga' ${ }^{1}$ - Yukinori Kurokawa ${ }^{2} \cdot$ Ryunosuke Machida $^{3} \cdot$ Yuya Sato $^{3} \cdot$ Shuji Takiguchi $^{2} \cdot$ Yuichiro Doki $^{2}$. \\ Hiroshi Yabusaki ${ }^{4}$ Masaya Watanabe ${ }^{5}$. Shinji Hato ${ }^{6} \cdot$ Mikihito Nakamori $^{7}$ - Seiji Ito ${ }^{8}$ Takaki Yoshikawa $^{9}$. \\ Masanori Terashima ${ }^{10}$
}

Received: 12 March 2020 / Accepted: 20 June 2020 / Published online: 29 June 2020

(c) The International Gastric Cancer Association and The Japanese Gastric Cancer Association 2020

\begin{abstract}
Background Recent studies have found a negative impact of postoperative complications on long-term survival outcomes, but it has not been confirmed by data obtained from a prospective study with a large sample size. This study investigated the impact of postoperative complications on long-term survival outcomes, and considered the optimal definition of complication, using data from JCOG1001, which compared bursectomy and non-bursectomy for patients with cT3/4a locally advanced gastric cancer.

Methods This study included 1191 of 1204 patients enrolled in the JCOG1001 trial. Complications were graded by ClavienDindo (C-D) classification. Impact of the grade ( $\geq$ C-D grade II or $\geq$ grade III) or type (any or intra-abdominal infectious) of complication on survival outcome was evaluated by univariate and multivariable analyses using the Cox proportional hazard model.

Results The incidence of any $\geq$ C-D grade II and $\geq$ grade III complication was $23.0 \%$ and $9.7 \%$, respectively, and that of $\geq$ grade II and $\geq$ grade III intra-abdominal infectious complication was $13.4 \%$ and $6.9 \%$, respectively. Multivariable analysis showed all four definitions of complications were independent prognostic factors for overall survival. Conversely, only any $\geq$ C-D grade III complication was found to be an independent prognostic factor for relapse-free survival (hazard ratio, 1.445; 95\% confidence interval, 1.026-2.036; $P=0.035$ ).

Conclusions Postoperative complications adversely affect the long-term survival outcomes of patients with cT3/4a gastric cancer. Any $\geq$ C-D grade III complication seems to be the most suitable definition of complication for predicting negative long-term survival outcomes.
\end{abstract}

Keywords Gastrectomy · Complication · Gastric cancer · Survival outcomes · Clavien-Dindo

Masanori Tokunaga

tokunaga.srg1@tmd.ac.jp

1 Department of Gastrointestinal Surgery, Tokyo Medical and Dental University, 1-5-45 Yushima, Bunkyo-ku, Tokyo, Japan

2 Department of Gastroenterological Surgery, Osaka University Graduate School of Medicine, Osaka, Japan

3 Japan Clinical Oncology Group Data Center/Operations Office, National Cancer Centre Hospital, Tokyo, Japan

4 Gastroenterological Surgery, Niigata Cancer Center Hospital, Niigata, Japan

5 Department of Gastroenterological Surgery, Shizuoka General Hospital, Shizuoka, Japan
6 Department of Gastroenterological Surgery, National Hospital Organization Shikoku Cancer Center, Matsuyama, Japan

7 Second Department of Surgery, School of Medicine, Wakayama Medical University, Wakayama, Japan

8 Department of Gastroenterological Surgery, Aichi Cancer Center Hospital, Nagoya, Japan

9 Gastric Surgery Division, National Cancer Center Hospital, Tokyo, Japan

10 Division of Gastric Surgery, Shizuoka Cancer Center, Nagaizumi, Japan 


\section{Introduction}

Gastric cancer is the fifth most common type of cancer, and the third leading cause of cancer-related deaths in the world [1]. Surgical resection with curative intent is the mainstay of treatment for locally advanced gastric cancer, and perioperative chemotherapy, postoperative chemotherapy, or postoperative chemoradiotherapy is usually administered, with regional preference, to improve long-term survival outcomes [2-6]. A D2 lymphadenectomy is recommended in several guidelines, and considered as the standard procedure for locally advanced gastric cancer. However, although the surgical technique of a D2 gastrectomy has been standardized in East Asia, it is still technically demanding [5-8]. Accordingly, the incidence of postoperative complications following D2 gastrectomy is reported to be 15-50\%, depending on the region [9-12]. Undoubtedly, postoperative complications adversely affect patient quality of life, and can even result in death, with the mortality rate following D2 gastrectomy reported to range from $0.5 \%$ to $10 \%$ [9-12].

Recent studies have found a negative impact of postoperative complications on long-term survival outcomes [13-18]. Although the mechanism has not yet been fully elucidated, one hypothesis is that the growth of residual cancer cells is stimulated by inflammatory cytokines and growth factors induced by surgical stress or postoperative complications [19, 20]. However, most reports have been from single-center, retrospective studies [13-16]. To date, the impact of complications on long-term survival outcomes has not been confirmed by data obtained from a prospective study with a large sample size. In addition, the definition of postoperative complication differs among studies; Tokunaga et al. [15] and Fujiya et al. [13] defined a Clavien-Dindo (C-D) grade II or higher intraabdominal infectious complication as a practical criterion, while Kubota et al. [14] adopted any $\geq$ C-D grade II complication as the definition [13-15]. On the other hand, Sierzega et al. [17] focused on anastomotic leakage, and they did not take the grade into account.

The objective of this study was to investigate the impact of postoperative complications on long-term survival outcomes using data from the Japan Clinical Oncology Group study 1001 (JCOG1001), a multicenter randomized controlled trial designed to confirm the superiority of bursectomy over omentectomy alone (non-bursectomy) for patients with cT3-4 locally advanced gastric cancer [12]. In addition, the optimal definition of complication for predicting long-term survival outcomes was examined by exploratory analysis.

\section{Patients and method}

\section{Patients}

In JCOG1001, patients 20-80 years of age who had cT3(SS)cT4a(SE), as per the 14th edition of the Japanese Classification of Gastric Carcinoma [21], histologically proven gastric adenocarcinoma with an Eastern Cooperative Oncology Group performance status of 0 or 1 , a body mass index less than $30 \mathrm{~kg} / \mathrm{m}^{2}$ and did not have distant metastasis or bulky lymph nodes, were randomly assigned (1:1) during surgery to receive either omentectomy alone (non-bursectomy) or bursectomy [12]. In total, 1204 patients were enrolled from June 2010 to March 2015 based on pre- and intra-operative inclusion and exclusion criteria, and 602 patients were allocated to each group. At the planned second interim analysis, the JCOG Data and Safety Monitoring Committee independently reviewed the results and recommended early publication on the basis of futility because overall survival (OS) was lower in the bursectomy group than in the non-bursectomy group. JCOG1001 was registered with UMIN-CTR, number UMIN000003688.

Of the 1204 patients, ten patients were ineligible, two patients did not have the allocated surgery, and one patient did not receive gastrectomy, leaving the remaining 1191 patients for inclusion in the present analysis. The median follow-up duration of 1191 patients was 3.6 months. All clinical data were obtained from JCOG1001 case report forms.

\section{Grading of postoperative complications}

In this study, the severity of postoperative complications was graded using the C-D classification [22, 23]

Because C-D grade I is regarded as clinically non-significant, only C-D grade II or more serious events ( $\geq$ C-D grade II) were defined as complications in the present study. Those with complications $\geq$ C-D grade III were defined as having severe complications. In addition, pancreatic fistula, anastomotic leakage, and intra-abdominal abscess were defined as intra-abdominal infectious complications.

\section{Statistical analysis}

Background data were compared between patients with and without any $\geq$ C-D grade II complication. Long-term survival outcomes were compared between patients with and without complications. In addition, independent prognostic factors were identified by multivariable analysis. These survival analyses were conducted according to four definitions of postoperative complication (any $\geq \mathrm{C}$-D grade II complication, any $\geq \mathrm{C}$-D grade III complication, $\geq \mathrm{C}$-D grade II 
intra-abdominal infectious complication, or $\geq$ C-D Grade III intra-abdominal infectious complication) to elucidate the most suitable definition of complication for predicting long-term survival outcomes.

Continuous variables are expressed as the median (range). The exact test was used for comparisons of categorical variables and the Wilcoxon rank-sum test for comparisons of continuous variables. The definitions of OS and relapse-free survival (RFS) were identical to those previously reported in JCOG1001. ${ }^{10}$ OS and RFS curves were estimated using the Kaplan-Meier method. OS and RFS were compared using a log-rank test. The hazard ratios (HRs) for OS and RFS were estimated by means of the Cox regression model. Multivariable analyses for OS and RFS were conducted using the Cox regression model, in which age ( $\leq 65 />65$ years), sex (male/female), body mass index $\left(<25 / \geq 25 \mathrm{~kg} / \mathrm{m}^{2}\right)$, Eastern Cooperative Oncology Group performance status (0/1), histological type (differentiated type/undifferentiated type), surgical procedure (distal gastrectomy/total gastrectomy), omentobursectomy (performed/not performed), pT (T1-2/T3/T4), $\mathrm{pN}(\mathrm{N} 0 / \mathrm{N} 1 / \mathrm{N} 2 / \mathrm{N} 3)$, and postoperative complication (yes/ no) were included as covariates. Multivariable analysis was conducted four times, once with each definition of complication. Two-sided $P$ values were calculated, and $P$ values less than 0.05 were considered to be significant. Statistical analyses were performed with SAS version 9.4.

\section{Results}

Details of postoperative complications are summarized in Table 1. Among the 1191 patients included in the present analysis, C-D grade I, II, IIIa, IIIb, IVa and IVb complications were observed in 134 (11.3\%), $159(13.3 \%)$, $79(6.6 \%), 28(2.4 \%), 4(0.3 \%)$, and 4 patients $(0.3 \%)$, respectively. Intra-abdominal infectious complications were observed in 251 patients $(21.1 \%)$, with a C-D grade of I in 92 (7.7\%), II in 77 (6.5\%), IIIa in 64 (5.4\%), IIIb in $15(1.3 \%)$, IVa in $1(0.1 \%)$, and IVb in $2(0.2 \%)$.

Three patients died within 30 days of surgery, and the causes of death were cerebral infarction on the 10th postoperative day (POD), aspiration pneumonia on 25 POD, and sepsis on 10 POD.

Table 1 Details of complications

\begin{tabular}{|c|c|c|c|c|c|c|c|c|c|c|}
\hline & \multicolumn{7}{|c|}{ C-D grade } & \multirow{2}{*}{$\begin{array}{l}\text { Any grade } \\
(\%)\end{array}$} & \multirow{2}{*}{$\begin{array}{l}\text { Grade II-IV } \\
(\%)\end{array}$} & \multirow{2}{*}{$\begin{array}{l}\text { Grade III-IV } \\
(\%)\end{array}$} \\
\hline & 0 & I & II & IIIa & $\mathrm{IIIb}$ & IVa & $\mathrm{IVb}$ & & & \\
\hline All complications & 783 & 134 & 159 & 79 & 28 & 4 & 4 & 34.3 & 23 & 9.7 \\
\hline $\begin{array}{l}\text { Intra-abdominal infectious } \\
\text { complications }\end{array}$ & 940 & 92 & 77 & 64 & 15 & 1 & 2 & 21.1 & 13.4 & 6.9 \\
\hline Anastomotic leakage & 1157 & 1 & 9 & 15 & 6 & 1 & 2 & 2.9 & 2.8 & 2 \\
\hline Pancreas-related infection & 988 & 96 & 62 & 39 & 6 & 0 & 0 & 17 & 9 & 3.8 \\
\hline Intra-abdominal abscess & 1116 & 0 & 27 & 38 & 8 & 1 & 1 & 6.3 & 6.3 & 4 \\
\hline Other complications & 947 & 85 & 103 & 36 & 14 & 3 & 3 & 20.5 & 13.4 & 4.7 \\
\hline Postoperative bleeding & 1171 & 8 & 4 & 5 & 3 & 0 & 0 & 1.7 & 1 & 0.7 \\
\hline Anastomotic stenosis & 1183 & 0 & 3 & 5 & 0 & - & - & 0.7 & 0.2 & 0 \\
\hline Cholecystitis & 1183 & 1 & 4 & 2 & 1 & 0 & 0 & 0.7 & 0.6 & 0.3 \\
\hline Dumping syndrome & 1181 & 8 & 2 & - & 0 & - & - & 0.8 & 0.2 & 0 \\
\hline Delayed gastric emptying & 1157 & 9 & 25 & - & 0 & - & - & 2.9 & 2.1 & 0 \\
\hline Reflux esophagitis & 1185 & 4 & 2 & - & 0 & - & - & 0.5 & 0.2 & 0 \\
\hline Obstructive ileus & 1176 & 1 & 5 & 2 & 7 & 0 & 0 & 1.3 & 1.2 & 0.8 \\
\hline Paralytic ileus & 1162 & 5 & 18 & 5 & 1 & 0 & 0 & 2.4 & 2 & 0.5 \\
\hline Thromboembolism & 1183 & 2 & 4 & 1 & 0 & 0 & 1 & 0.7 & 0.5 & 0.2 \\
\hline Pneumonia & 1159 & 0 & 26 & 1 & 0 & 3 & 2 & 2.7 & 2.7 & 0.5 \\
\hline Pleural effusion & 1127 & 41 & 4 & 17 & 1 & 0 & 1 & 5.4 & 1.9 & 1.6 \\
\hline Chylous ascites & 1174 & 13 & 3 & 0 & 0 & - & - & 1.3 & 0.3 & 0 \\
\hline Wound infection & 1153 & 13 & 22 & 1 & 1 & 0 & 1 & 3.2 & 2.1 & 0.3 \\
\hline Wound dehiscence & 1174 & 6 & 7 & 3 & 1 & 0 & 0 & 1.4 & 0.9 & 0.3 \\
\hline
\end{tabular}

C-D indicates Clavien-Dindo

Values are numbers of patients, unless indicated otherwise 


\section{Comparisons between patients} with and without any $\geq$ C-D grade III complications

Demographic data and clinical characteristics were compared between patients with and without any $\geq C$-D grade III complications (Table 2). There were significant differences in sex, tumor location, type of gastrectomy, performance of splenectomy, operation time, and blood loss. The proportion of patients receiving adjuvant chemotherapy was also different between the two groups. In detail, the proportion of patients receiving adjuvant chemotherapy was $61.0 \%(478 / 783)$ in cases without any complication, and was 65.7\% (88/134), 66.0\% (105/159), $53.3 \%$ (57/107), and $12.5 \%$ (1/8), in cases with C-D grade I, II, III, and IV complication, respectively.
Table 2 Clinicopathological characteristics in patients with and without any $\geq$ ClavienDindo grade II complication

\begin{tabular}{|c|c|c|c|}
\hline & Grade $0-$ II $(n=1076)$ & Grade III-IV $(n=115)$ & $P$ value \\
\hline Age, median (range), y & $66(29-80)$ & $69(29-73)$ & 0.051 \\
\hline \multicolumn{4}{|l|}{ Sex } \\
\hline Male & $734(68)$ & 101 & \\
\hline Female & $342(32)$ & 14 & $<0.001$ \\
\hline \multicolumn{4}{|l|}{ Tumor location } \\
\hline Upper third & $225(21)$ & $46(40)$ & \\
\hline Middle third & $421(39)$ & $36(31)$ & \\
\hline Lower third & $430(40)$ & $33(29)$ & $<0.001$ \\
\hline \multicolumn{4}{|l|}{ Histological type } \\
\hline Differentiated type & $574(53)$ & $62(54)$ & \\
\hline Undifferentiated type & $502(47)$ & $53(46)$ & 0.922 \\
\hline \multicolumn{4}{|l|}{ Type of gastrectomy } \\
\hline Total gastrectomy & $352(33)$ & $60(52)$ & \\
\hline Distal gastrectomy & $724(67)$ & $55(48)$ & $<0.001$ \\
\hline \multicolumn{4}{|l|}{ Splenectomy } \\
\hline Yes & $275(26)$ & $52(45)$ & \\
\hline No & $801(74)$ & $63(55)$ & $<0.001$ \\
\hline \multicolumn{4}{|l|}{ Lymph node dissection } \\
\hline Less than D2 & $11(1)$ & $0(0)$ & \\
\hline D2 or more & 1065 (99) & $115(100)$ & 0.613 \\
\hline \multicolumn{4}{|l|}{ Bursectomy } \\
\hline Bursectomy & $526(49)$ & $67(58)$ & \\
\hline Non-bursectomy & $550(51)$ & $48(42)$ & 0.062 \\
\hline Operation time, median (range), min & $233(80-630)$ & $280(102-473)$ & $<0.001$ \\
\hline Blood loss, median (range), $\mathrm{mL}$ & $266(0-3068)$ & $415(8-2140)$ & $<0.001$ \\
\hline \multicolumn{4}{|l|}{ Blood transfusion } \\
\hline No & $1029(96)$ & $107(93)$ & \\
\hline Yes & $47(4)$ & $8(7)$ & 0.237 \\
\hline \multicolumn{4}{|l|}{ Pathological stage } \\
\hline I & $141(13)$ & $14(12)$ & \\
\hline II & $392(36)$ & $31(27)$ & \\
\hline III & $466(43)$ & $60(52)$ & \\
\hline IV & $77(7)$ & $10(9)$ & 0.168 \\
\hline \multicolumn{4}{|l|}{ Residual tumor } \\
\hline R0 & $1001(93)$ & $104(90)$ & 0.360 \\
\hline $\mathrm{R} 1 / 2$ & $75(7)$ & $11(10)$ & 0.340 \\
\hline \multicolumn{4}{|l|}{ Postoperative adjuvant chemotherapy } \\
\hline No & $405(38)$ & $57(50)$ & \\
\hline Yes & $671(62)$ & $58(50)$ & 0.036 \\
\hline
\end{tabular}

Values are $n(\%)$, unless otherwise indicated 


\section{OS and RFS}

OS curves according to the four definitions of complication are illustrated in Fig. 1a-d. OS was worse in patients with complications irrespective of the definition: The univariate HR was 1.471 (95\% confidence interval [CI], 1.104-1.961; $P=0.008)$ for any $\geq$ C-D grade II complication, $1.723(95 \%$ CI, 1.184-2.507; $P=0.004$ ) for any $\geq C$-D Grade III complication, 1.455 (95\% CI, 1.029-2.057; $P=0.033$ ) for $\geq \mathrm{C}-\mathrm{D}$ grade II intra-abdominal infectious complications, and 1.635 (95\% CI, 1.042-2.564; $P=0.031$ ) for $>$ C-D grade III intraabdominal infectious complications.

RFS curves are shown in Fig. 2a-d. RFS was worse in patients with any $\geq C$-D grade II complication (HR, 1.300; 95\% CI, $1.016-1.663 ; P=0.036$ ) or any $\geq \mathrm{C}$-D grade III complication (HR, 1.450; 95\% CI, 1.037-2.027; $P=0.029$ ), but it was not significantly different between patients with and without $\geq C$-D grade II intra-abdominal infectious complications (HR, 1.275; 95\% CI, 0.943-1.724; $P=0.114$ ) or $\geq C$-D grade III intra-abdominal infectious complications (HR, 1.383; 95\% CI, 0.926-2.066; $P=0.111$ ).

\section{Multivariable analysis}

The results of multivariable analysis for OS are summarized in Table 3. Multivariable analysis was conducted four times, once with each definition of complication. Complication was identified as an independent prognostic factor, irrespective of the definition. When we adopted any $\geq C$-D grade II complication as the definition, the HR was 1.422 (95\% CI, 1.054-1.918; $P=0.021$ ), and was 1.719 (95\% CI, $1.172-2.524 ; P=0.006)$ with any $\geq \mathrm{C}$-D grade III complication as the definition. Similarly, $\geq$ C-D grade II intraabdominal infectious complications (HR, 1.494; 95\% CI, $1.040-2.147 ; P=0.030)$ and $\geq C$-D grade III intra-abdominal infectious complications (HR, 1.670; 95\% CI, 1.055-2.643; $P=0.029)$ were also identified as independent prognostic factors for OS.

On the other hand, only a $\geq$ C-D grade III complication of any type was found to be an independent prognostic factor for RFS (HR, 1.445; 95\% CI, 1.026-2.036; $P=0.035$ ), and the other definitions, including any $\geq \mathrm{C}$-D grade II complication (HR, 1.215; 95\% CI, 0.941-1.569; $P=0.134), \geq$ C-D grade II intra-abdominal infectious complications (HR, $1.290 ; 95 \%$ CI, $0.940-1.769 ; P=0.115)$, and $\geq \mathrm{C}$-D grade III intra-abdominal infectious complications (HR, 1.447; 95\% CI, 0.961-2.181; $P=0.077$ ) were not identified as independent prognostic factors for RFS (Table 4).

\section{Discussion}

The present study clearly demonstrates that postoperative complications are associated with poor OS, irrespective of the type or grade of complication. In addition, any $\geq C$-D grade III complication is associated with a poor RFS and

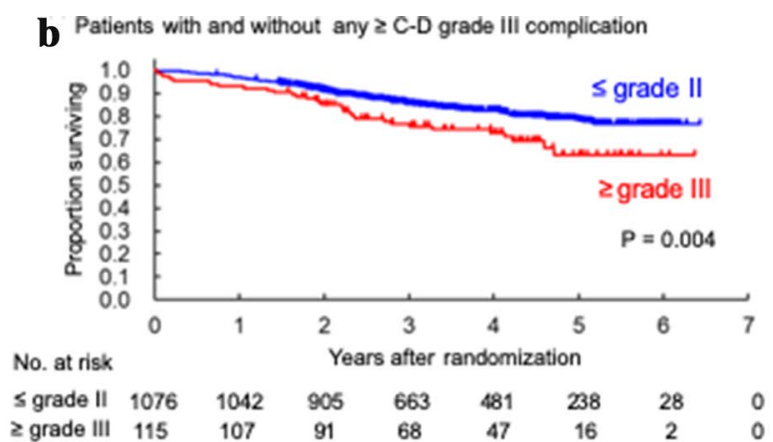

d Patients with and without $\geq$ C-D grade III intraabdominal infectious complication

C Patients with and without $\geq C$-D grade II intraabdominal infectious complication

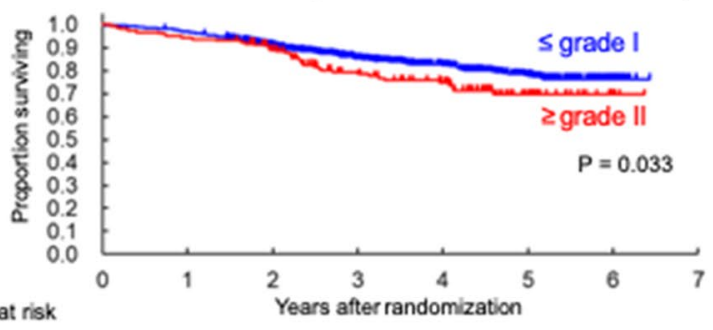

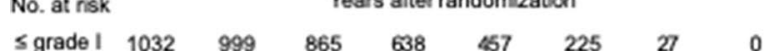

$\begin{array}{lllllllll}z \text { grade II } & 159 & 150 & 131 & 93 & 71 & 29 & 3 & 0\end{array}$

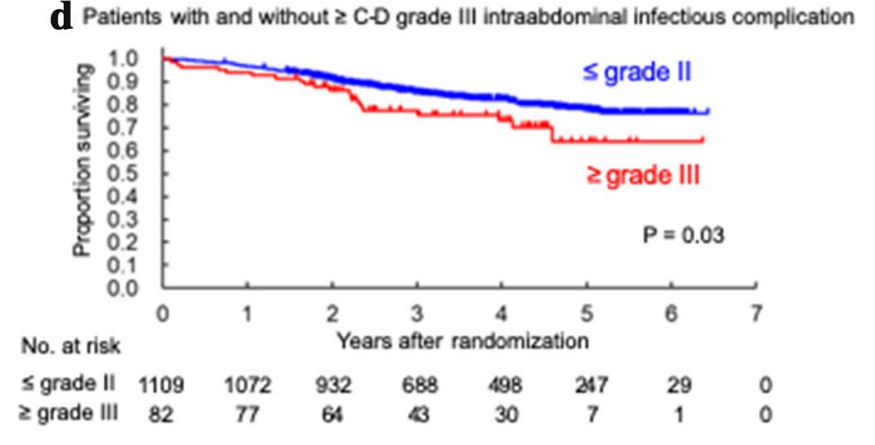

Fig. 1 Kaplan-Meier estimates for overall survival according to $\mathbf{a}$ any $\geq$ Clavien-Dindo (C-D) grade II complication, $\mathbf{b}$ any $\geq$ CD grade III complication, $\mathbf{c} \geq \mathrm{CD}$ grade II intra-abdominal infectious complications, and $\mathbf{d} \geq \mathrm{CD}$ grade III intra-abdominal infectious complications 
a Patients with and without any $\geq C-D$ grade II complication

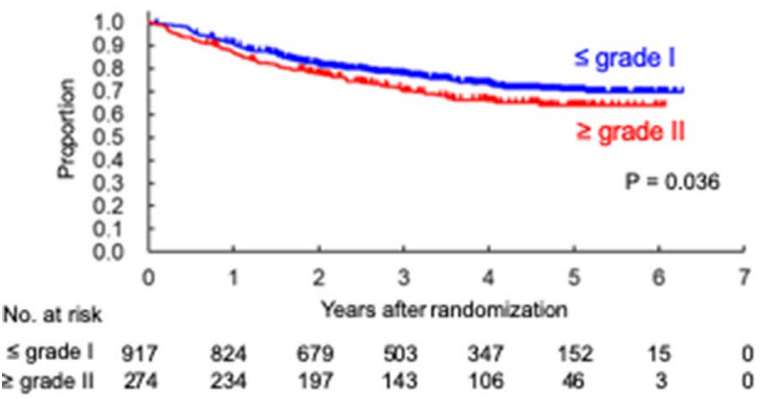

C Patients with and without $\geq C-D$ grade II intraabdominal infectious complication

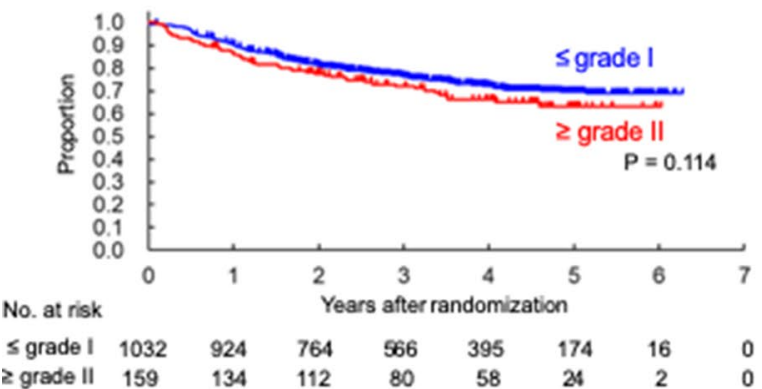

b Patients with and without any $\geq C-D$ grade III complication

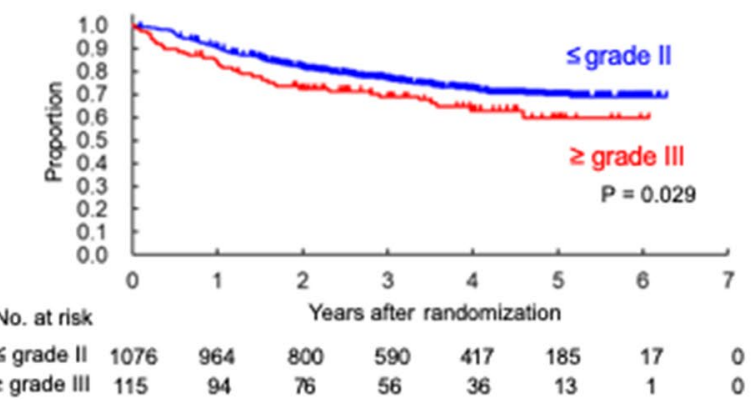

d Patients with and without $\geq \mathrm{C}-\mathrm{D}$ grade III intraabdominal infectious complication

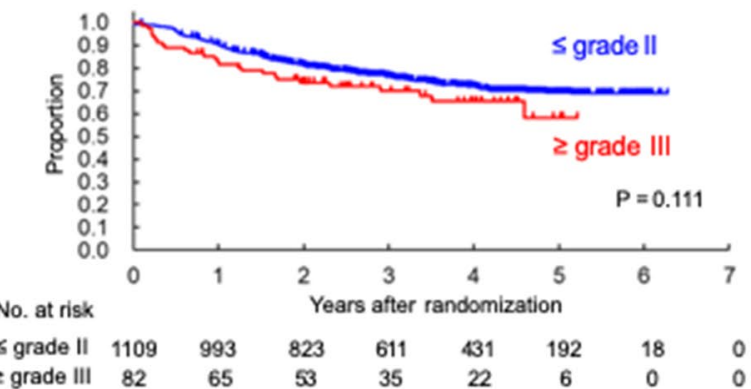

Fig. 2 Kaplan-Meier estimates for relapse-free survival according to a any $\geq$ Clavien-Dindo (C-D) grade II complication, $\mathbf{b}$ any $\geq$ CD grade III complication, $\mathbf{c} \geq \mathrm{CD}$ grade II intra-abdominal infectious complications, and $\mathbf{d} \geq \mathrm{CD}$ grade III intra-abdominal infectious complications

identified as an independent prognostic factor for RFS. This is the first report in which the most suitable definition of complication, in terms of predicting both poor OS and RFS, was demonstrated using the data obtained from a prospective randomized clinical trial, and any $\geq$ C-D grade III complication seems to be the most suitable.

At the planned second interim analysis of JCOG1001 which was conducted after the completion of patient accrual, the JCOG Data and Safety Monitoring Committee independently reviewed the results and recommended early publication, because OS was slightly lower in the bursectomy group than in the non-bursectomy group, and the predictive probability of OS being significantly higher in the bursectomy group than in the non-bursectomy group at the final analysis was only $12.7 \%$. One of the possible reasons for the negative result in JCOG1001 is the slightly higher incidence of any $\geq C$-D grade II complication in the bursectomy group (54\% vs. $46 \%$ ), which could have resulted in growth stimulation of residual cancer cells by inflammatory cytokines and growth factors, induced by surgical stress or postoperative complications. Previous studies had shown that postoperative complications, such as anastomotic leakage, pancreatic fistula, and abdominal abscess, have a negative effect on survival in patients with gastric cancer [13-17]. The results of the present study also support our speculation, and it is vital to avoid postoperative complications, not only for better early surgical outcomes, but also to improve long-term survival outcomes.

Another objective of our study was to explore the most suitable definition of postoperative complication, in terms of predicting long-term survival outcomes. All the four definitions adopted in the present study (any $\geq C D$ grade II, any $\geq C D$ grade III, $\geq$ CD grade II intra-abdominal infectious, and $\geq C D$ grade III intra-abdominal infectious complications) were found to be associated with a worse OS, with a slightly higher HR for any $\geq C D$ grade III complication. On the other hand, only any $\geq C D$ grade III complication was associated with poor RFS, and was identified as an independent prognostic factor for RFS. Considering this result, and the higher HR for $\geq C$-D grade III than $\geq$ C-D grade II, irrespective of the type of complication, the grade of complication seems more important than the type of complication in predicting longterm survival outcomes. A possible reason for a higher HR with $\geq \mathrm{C}$-D grade III complications is that the more severe the complication, the higher the levels of inflammatory cytokines and growth factors, which could stimulate the growth of residual cancer cells $[19,20]$. Indeed, the correlation between C-reactive protein (CRP) elevation, a comprehensive indicator of inflammation, and survival outcomes has been reported, implying that postoperative inflammation, induced by complications, might be the key factor for tumor progression and worsen survival outcomes 
Table 3 Resuts of multivariable analysis for overall survival with different definition of complications

\begin{tabular}{|c|c|c|c|c|}
\hline \multirow[t]{2}{*}{ Variables } & \multirow{2}{*}{$\begin{array}{l}\text { Any } \geq \text { C-D grade II complica- } \\
\text { tion }\end{array}$} & \multicolumn{2}{|c|}{ Hazard ratios [95\% confidence intervals] } & \multirow{2}{*}{$\begin{array}{l}\geq \mathrm{C} \text {-D grade III intra- } \\
\text { abdominal infectious } \\
\text { complications }\end{array}$} \\
\hline & & $\begin{array}{l}\text { Any } \geq \text { C-D grade III complica- } \\
\text { tion }\end{array}$ & $\begin{array}{l}\geq \mathrm{C} \text {-D grade II intra-abdomi- } \\
\text { nal infectious complications }\end{array}$ & \\
\hline \multicolumn{5}{|l|}{ Age } \\
\hline$\leq 65$ & 1 & 1 & 1 & 1 \\
\hline$>65$ & $1.328[1.012-1.743]^{*}$ & $1.345[1.025-1.764]^{*}$ & $1.345[1.025-1.764]^{*}$ & $1.341[1.022-1.760]^{*}$ \\
\hline \multicolumn{5}{|l|}{ Sex } \\
\hline Male & 1 & 1 & 1 & 1 \\
\hline Female & $0.846[0.620-1.155]$ & $0.850[0.622-1.161]$ & $0.848[0.621-1.159]$ & $0.836[0.613-1.141]$ \\
\hline \multicolumn{5}{|l|}{ Body mass index } \\
\hline$<25$ & 1 & 1 & 1 & 1 \\
\hline$\geq 25$ & $0.994[0.717-1.377]$ & $1.014[0.733-1.403]$ & $0.987[0.711-1.369]$ & $1.007[0.728-1.394]$ \\
\hline \multicolumn{5}{|c|}{ ECOG performance status } \\
\hline 0 & 1 & 1 & 1 & 1 \\
\hline 1 & $2.208[1.263-3.858]^{*}$ & $2.213[1.268-3.862]^{*}$ & $2.143[1.227-3.743]^{*}$ & $2.208[1.264-3.857]^{*}$ \\
\hline \multicolumn{5}{|l|}{ Histological type } \\
\hline Differentiated & 1 & 1 & 1 & 1 \\
\hline Undifferentiated & $1.206[0.913-1.592]$ & $1.204[0.911-1.591]$ & $1.185[0.896-1.566]$ & $1.205[0.912-1.591]$ \\
\hline \multicolumn{5}{|l|}{ Surgical procedure } \\
\hline Distal gastrectomy & 1 & 1 & 1 & 1 \\
\hline Total gastrectomy & $1.044[0.788-1.384]$ & $1.075[0.814-1.420]$ & $1.055[0.796-1.398]$ & $1.096[0.831-1.445]$ \\
\hline \multicolumn{5}{|l|}{ Omentobursectomy } \\
\hline Performed & 1 & 1 & 1 & 1 \\
\hline Not performed & 0.913 [0.699-1.193] & 0.916 [0.701-1.197] & 0.906 [0.694-1.183] & 0.913 [0.699-1.192] \\
\hline \multicolumn{5}{|l|}{$\mathrm{pT}$} \\
\hline $\mathrm{T} 1, \mathrm{~T} 2$ & 1 & 1 & 1 & 1 \\
\hline $\mathrm{T} 3$ & 1.396 [0.798-2.444] & 1.364 [0.778-2.390] & 1.390 [0.794-2.433] & 1.365 [0.779-2.393] \\
\hline $\mathrm{T} 4$ & $2.986[1.730-5.154]^{*}$ & $2.900[1.680-5.006]^{*}$ & $2.989[1.732-5.159]^{*}$ & $2.908[1.684-5.020]^{*}$ \\
\hline \multicolumn{5}{|l|}{$\mathrm{pN}$} \\
\hline No & 1 & 1 & 1 & 1 \\
\hline N1 & 1.559 [0.905-2.683] & 1.609 [0.933-2.773] & $1.557[0.904-2.680]$ & $1.600[0.928-2.758]$ \\
\hline $\mathrm{N} 2$ & $1.854[1.131-3.040]^{*}$ & $1.860[1.134-3.049]^{*}$ & $1.850[1.128-3.034]^{*}$ & $1.866[1.138-3.059]^{*}$ \\
\hline N3 & $4.673[2.995-7.290]^{*}$ & $4.826[3.090-7.536]^{*}$ & $4.712[3.021-7.352]^{*}$ & $4.797[3.072-7.490]^{*}$ \\
\hline \multicolumn{5}{|l|}{ Complication } \\
\hline No & 1 & 1 & 1 & 1 \\
\hline Yes & $1.422[1.054-1.918]^{*}$ & $1.719[1.171-2.524]^{*}$ & $1.494[1.040-2.147]^{*}$ & $1.670[1.055-2.643]^{*}$ \\
\hline
\end{tabular}

$* P<0.05$

C-D indicates Clavien-Dindo, ECOG Eastern Cooperative Oncology Group

[24]. Nonetheless, when the incidence of complications is included as an endpoint in future clinical trials evaluating the efficacy of surgical treatment, any $\geq \mathrm{CD}$ grade III complication should be selected.

The result should be integrated into our daily practice, and survival outcomes could be improved by reducing the incidence of $\geq$ CD III complication. It seems difficult to decrease the incidence itself, considering that surgeons already devote their best efforts toward reducing postoperative complications. However, we may be able to prevent complications from becoming more severe by paying special attention to the postoperative clinical course, and commencing medical treatment as early as possible.

In this study, the influence of differing types of complications on survival outcomes was evaluated by including four different definitions of complication in four separate multivariable models. It is generally considered that $\geq C D$ grade III intra-abdominal infectious complications strongly affect survival outcomes because they seem to cause more inflammation in stimulating tumor cells than other complications. However, in the present study, only any $\geq$ CD grade III complication was identified as an independent prognostic factor 
Table 4 Resuts of multivariable analysis for relapse-free survival with different definition of complications

\begin{tabular}{|c|c|c|c|c|}
\hline \multirow[t]{2}{*}{ Variables } & \multirow{2}{*}{$\begin{array}{l}\text { Any } \geq C \text {-D grade II complica- } \\
\text { tion }\end{array}$} & \multicolumn{2}{|c|}{ Hazard ratios [95\% confidence intervals] } & \multirow{2}{*}{$\begin{array}{l}\geq \mathrm{C} \text {-D grade III intra- } \\
\text { abdominal infectious } \\
\text { complications }\end{array}$} \\
\hline & & $\begin{array}{l}\text { Any } \geq \mathrm{C} \text {-D grade III complica- } \\
\text { tion }\end{array}$ & $\begin{array}{l}\geq \mathrm{C} \text {-D grade II intra-abdomi- } \\
\text { nal infectious complications }\end{array}$ & \\
\hline \multicolumn{5}{|l|}{ Age } \\
\hline$\leq 65$ & 1 & 1 & 1 & 1 \\
\hline$>65$ & $1.192[0.953-1.492]$ & $1.200[0.959-1.501]$ & $1.200[0.959-1.501]$ & $1.195[0.955-1.496]$ \\
\hline \multicolumn{5}{|l|}{ Sex } \\
\hline Male & 1 & 1 & 1 & 1 \\
\hline Female & $0.892[0.692-1.151]$ & $0.897[0.695-1.157]$ & $0.896[0.694-1.156]$ & $0.890[0.691-1.148]$ \\
\hline \multicolumn{5}{|l|}{ Body mass index } \\
\hline$<25$ & 1 & 1 & 1 & 1 \\
\hline$\geq 25$ & $0.952[0.724-1.252]$ & $0.951[0.723-1.250]$ & $0.946[0.718-1.245]$ & $0.948[0.720-1.247]$ \\
\hline \multicolumn{5}{|c|}{ ECOG performance status } \\
\hline 0 & 1 & 1 & 1 & 1 \\
\hline 1 & $1.902[1.183-3.057]^{*}$ & $1.903[1.184-3.057]^{*}$ & $1.873[1.165-3.011]^{*}$ & $1.915[1.191-3.079]^{*}$ \\
\hline \multicolumn{5}{|l|}{ Histological type } \\
\hline Differentiated & 1 & 1 & 1 & 1 \\
\hline Undifferentiated & 1.101 [0.874-1.389] & $1.102[0.874-1.390]$ & $1.091[0.865-1.377]$ & $1.100[0.873-1.388]$ \\
\hline \multicolumn{5}{|l|}{ Surgical procedure } \\
\hline Distal gastrectomy & 1 & 1 & 1 & 1 \\
\hline Total gastrectomy & 1.134 [0.899-1.430] & 1.144 [0.910-1.438] & $1.131[0.896-1.427]$ & $1.156[0.920-1.452]$ \\
\hline \multicolumn{5}{|l|}{ Omentobursectomy } \\
\hline Performed & 1 & 1 & 1 & 1 \\
\hline Not performed & $0.873[0.700-1.090]$ & $0.876[0.702-1.093]$ & $0.869[0.697-1.084]$ & $0.872[0.699-1.088]$ \\
\hline \multicolumn{5}{|l|}{ pT } \\
\hline $\mathrm{T} 1, \mathrm{~T} 2$ & 1 & 1 & 1 & 1 \\
\hline $\mathrm{T} 3$ & $1.422[0.915-2.208]$ & 1.404 [0.903-2.182] & 1.422 [0.915-2.209] & $1.403[0.902-2.181]$ \\
\hline $\mathrm{T} 4$ & $2.507[1.626-3.864]^{*}$ & $2.480[1.609-3.824]^{*}$ & $2.520[1.635-3.885]^{*}$ & $2.480[1.609-3.824]^{*}$ \\
\hline \multicolumn{5}{|l|}{$\mathrm{pN}$} \\
\hline No & 1 & 1 & 1 & 1 \\
\hline N1 & $1.537[0.974-2.426]$ & $1.565[0.991-2.473]$ & $1.538[0.975-2.428]$ & $1.561[0.988-2.466]$ \\
\hline $\mathrm{N} 2$ & $2.660[1.786-3.963]^{*}$ & $2.664[1.788-3.970]^{*}$ & $2.655[1.782-3.955]^{*}$ & $2.672[1.793-3.981]^{*}$ \\
\hline N3 & $5.082[3.493-7.394]^{*}$ & $5.187[3.563-7.550]^{*}$ & $5.118[3.518-7.444]^{*}$ & $5.176[3.556-7.535]^{*}$ \\
\hline \multicolumn{5}{|l|}{ Complication } \\
\hline No & 1 & 1 & 1 & 1 \\
\hline Yes & 1.215 [0.941-1.569] & $1.445[1.026-2.036]^{*}$ & $1.290[0.940-1.769]$ & $1.447[0.961-2.181]$ \\
\hline
\end{tabular}

$* P<0.05$

C-D indicates Clavien-Dindo; ECOG, Eastern Cooperative Oncology Group

for both OS and RFS. The proportion of patients with grade IIIb or higher complication was $22 \%$ (18/82) in $\geq$ CD grade III intraabdominal infectious complication, while it was $36 \%$ (20/56) in $\geq$ CD grade III "non" intra-abdominal infectious complication. This difference in distribution of grade IIIb or higher might have resulted in the stronger impact of any $\geq \mathrm{CD}$ grade III complication on survival outcomes.

There were differences in clinicopathological characteristics between patients with and without any $\geq C$-D grade III complication. Among them, surgical procedure and intraoperative findings were significantly different between the groups, implying that total gastrectomy, usually performed for upper-third gastric cancer, is associated with a longer operation time, higher blood loss, and a higher incidence of postoperative complication. Surgical procedure, tumor location, intra-operative blood loss, and operation time seem to be intermediate factors, and thus we included only the type of gastrectomy as a covariate for the multivariable analysis.

Adjuvant chemotherapy with S-1, which is a standard treatment for pStage II/III gastric cancer in Japan and was integrated as a protocol treatment in JCOG1001 [6, $25,26]$, was commenced less frequently in patients with 
any $\geq$ C-D grade III complication (58/115) than those with grade II complication (105/159) or grade 0/I complication (566/917). This result would be expected, since patients with $\geq$ C-D grade III complication require longer hospital stays, and their deteriorated physical status would make commencement of adjuvant chemotherapy difficult. Neoadjuvant chemotherapy, which is not affected by postoperative clinical course including complication, seems a plausible option in addressing the non-negligible incidence $(10 \%)$ of $\geq$ C-D grade III complication.

Not only postoperative complication but also other factors would affect postoperative immune function. For example, Minimally-invasive surgeries, such as laparoscopic and robotic gastrectomy, have less impact on immune function than open surgery, and therefore patients suffering postoperative complications would be affected differently compared to those undergoing open gastrectomy [27-29]. It is unclear if postoperative complication following minimally invasive surgeries has less or more impact on long-term survival outcomes, and this issue needs to be clarified in the future. Splenectomy also affects postoperative immune function. Watanabe et al. reported that the negative effect of postoperative complication on survival was canceled in patients undergoing splenectomy [30]. Perioperative transfusion, which causes dysfunction of the immune system and malignant transformation of neoplastic cells, is reportedly associated with worse survival outcomes following gastrectomy [31], but this negative impact was also canceled by splenectomy $[32,33]$. Various factors which affect the immune system are likely to have an impact on survival outcomes, and these should be comprehensively taken into account.

The present study has several limitations. First, it is still unclear whether complications themselves cause worse survival outcomes, or if they tend to develop in patients with intrinsic characteristics making them more likely to have worse survival outcomes. Nevertheless, surgeons need to be mindful of the fact that postoperative complications are associated with both early and long-term negative surgical outcomes. Second, the observation period of patients is relatively short in the present study because the results of JCOG1001 were released at the interim analysis, and thus these results will need to be confirmed using matured survival outcome data in the future.

In conclusion, the present study is the first to clearly demonstrate the adverse effects of postoperative complications on long-term survival outcomes using data from a prospective clinical trial, and shows that any $\geq$ C-D grade III complication seems to be the most suitable definition of complication for predicting negative long-term survival outcomes. Although it may be impossible to avoid complications completely, surgeons should try to prevent complications from developing to $\geq$ C-D grade III. Neoadjuvant chemotherapy could be a promising treatment option because it is not affected by postoperative complication.

\section{Compliance with ethical standards}

Conflict of interest The authors declare that they have no conflict of interest.

Ethical standard All procedures followed were in accordance with the ethical standards of the responsible committee on human experimentation (institutional and national) and with the Helsinki Declaration of 1964 and later versions.

\section{References}

1. Bray F, Ferlay J, Soerjomataram I, et al. Global cancer statistics 2018: GLOBOCAN estimates of incidence and mortality worldwide for 36 cancers in 185 countries. CA Cancer J Clin. 2018;68:394-424.

2. Al-Batran SE, Homann N, Pauligk C, et al. FLOT4-AIO Investigators. Perioperative chemotherapy with fluorouracil plus leucovorin, oxaliplatin, and docetaxel versus fluorouracil or capecitabine plus cisplatin and epirubicin for locally advanced, resectable gastric or gastro-oesophageal junction adenocarcinoma (FLOT4): a randomised, phase 2/3 trial. Lancet. 2019;393:1948-1957.

3. Bang YJ, Kim YW, Yang HK, et al. CLASSIC trial investigators. Adjuvant capecitabine and oxaliplatin for gastric cancer after D2 gastrectomy (CLASSIC): a phase 3 open-label, randomised controlled trial. Lancet. 2012;379:315-321.

4. Cunningham D, Allum WH, Stenning SP, et al. Perioperative chemotherapy versus surgery alone for resectable gastroesophageal cancer. N Engl J Med. 2006;355:11-20.

5. Macdonald JS, Smalley SR, Benedetti J, et al. Chemoradiotherapy after surgery compared with surgery alone for adenocarcinoma of the stomach or gastroesophageal junction. N Engl J Med. 2001;345:725-30.

6. Sakuramoto S, Sasako M, Yamaguchi T, et al. ACTS-GC Group. Adjuvant chemotherapy for gastric cancer with S-1, an oral fluoropyrimidine. N Engl J Med. 2007;357:1810-1820.

7. Waddell T, Verheij M, Allum W, et al. Gastric cancer: ESMOESSO-ESTRO clinical practice guidelines for diagnosis, treatment and follow-up. Eur J Surg Oncol. 2014;40:584-91.

8. Japanese Gastric Cancer Association. Japanese gastric cancer treatment guidelines 2014 (ver. 4). Gastric Cancer. 2017;20:1-19.

9. Sano T, Sasako M, Yamamoto S, et al. Gastric Cancer Surgical Study Group of the Japan Clinical Oncology Group. Gastric cancer surgery: morbidity and mortality results from a prospective randomized controlled trial comparing D2 and extended paraaortic lymphadenectomy--Japan Clinical Oncology Group study 9501. J Clin Oncol. 2004;22:2767-2773.

10. Bonenkamp JJ, Songun I, Hermans J, et al. Randomised comparison of morbidity after D1 and D2 dissection for gastric cancer in 996 Dutch patients. Lancet. 1995;345:745-8.

11. Cuschieri A, Fayers P, Fielding J, et al. Postoperative morbidity and mortality after D1 and D2 resections for gastric cancer: preliminary results of the MRC randomised controlled surgical trial. The Surgical Cooperative Group Lancet. 1996;347:995-9.

12. Kurokawa Y, Doki Y, Mizusawa J, et al. Bursectomy versus omentectomy alone for resectable gastric cancer (JCOG1001): a phase 3, open-label, randomised controlled trial. Lancet Gastroenterol Hepatol. 2018;3:460-8. 
13. Fujiya K, Tokunaga M, Mori K, et al. Long-term survival in patients with postoperative intra-abdominal infectious complications after curative gastrectomy for gastric cancer: A propensity score matching analysis. Ann Surg Oncol. 2016;23:809-16.

14. Kubota T, Hiki N, Sano T, et al. Prognostic significance of complications after curative surgery for gastric cancer. Ann Surg Oncol. 2014;21:891-8.

15. Tokunaga M, Sano T, Ohyama S, et al. Clinicopathological characteristics and survival difference between gastric stump carcinoma and primary upper third gastric cancer. J Gastrointest Surg. 2013;17:313-8.

16. Tsujimoto H, Ichikura $\mathrm{T}$, Ono $\mathrm{S}$, et al. Impact of postoperative infection on long-term survival after potentially curative resection for gastric cancer. Ann Surg Oncol. 2009;16:311-8.

17. Sierzega M, Kolodziejczyk P, Kulig J. Polish Gastric Cancer Study Group. Impact of anastomotic leakage on long-term survival after total gastrectomy for carcinoma of the stomach. Br J Surg. 2010;97:1035-1042.

18. Shimada H, Fukagawa T, Haga Y, Oba H. Does postoperative morbidity worsen the oncological outcome after radical surgery for gastrointestinal cancers? A systematic review of the literature. Ann Gastroenterol surg. 2017;1:11-23.

19. Goldfarb Y, Sorski L, Benish M, et al. Improving postoperative immune status and resistance to cancer metastasis: a combined perioperative approach of immunostimulation and prevention of excessive surgical stress responses. Ann Surg. 2011;253:798-810.

20. Sietses C, Beelen RH, Meijer S, et al. Immunological consequences of laparoscopic surgery, speculations on the cause and clinical implications. Langenbecks Arch Surg. 1999;384:250-8.

21. Japanese Gastric Cancer Association. Japanese classification of gastric carcinoma: 3rd English edition. Gastric Cancer. 2011;14:101-112.

22. Dindo D, Demartines N, Clavien PA. Classification of surgical complications: a new proposal with evaluation in a cohort of 6336 patients and results of a survey. Ann Surg. 2004;240:205-13.

23. Katayama H, Kurokawa Y, Nakamura K, et al. Extended ClavienDindo classification of surgical complications: Japan Clinical Oncology Group postoperative complications criteria. Surg Today. 2016;46:668-85.

24. Kurokawa Y, Yamashita K, Kawabata R, et al. Prognostic value of postoperative $\mathrm{C}$-reactive protein elevation versus complication occurrence: a multicenter validation study. Gastric Cancer. 2020.
25. Yoshida K, Kodera Y, Kochi M, et al. Addition of docetaxel to oral fluoropyrimidine improves efficacy in patients with stage III gastric cancer: Interim analysis of JACCRO GC-07, a randomized controlled trial. J Clin Oncol. 2019;37:1296-304.

26. Sasako M, Sakuramoto S, Katai H, et al. Five-year outcomes of a randomized phase III trial comparing adjuvant chemotherapy with S-1 versus surgery alone in stage II or III gastric cancer. J Clin Oncol. 2011;29:4387-93.

27. Inaki N, Etoh $\mathrm{T}$, Ohyama $\mathrm{T}$, et al. A multi-institutional, prospective, phase II feasibility study of laparoscopy-assisted distal gastrectomy with D2 lymph node dissection for locally advanced gastric cancer (JLSSG0901). World J Surg. 2015;39:2734-41.

28. Katai H, Mizusawa J, Katayama H, et al. Short-term surgical outcomes from a phase III study of laparoscopy-assisted versus open distal gastrectomy with nodal dissection for clinical stage IA/IB gastric cancer: Japan Clinical Oncology Group Study JCOG0912. Gastric Cancer. 2017;20:699-708.

29. Okholm C, Goetze JP, Svendsen LB, et al. Inflammatory response in laparoscopic vs. open surgery for gastric cancer. Scand J Gastroenterol. 2014;49:1027-1034.

30. Watanabe M, Kinoshita T, Tokunaga M, et al. Complications and their correlation with prognosis in patients undergoing total gastrectomy with splenectomy for treatment of proximal advanced gastric cancer. Eur J Surg Oncol. 2018;44:1181-5.

31. Kanda M, Kobayashi D, Tanaka C, et al. Adverse prognostic impact of perioperative allogeneic transfusion on patients with stage II/III gastric cancer. Gastric Cancer. 2016;19:255-63.

32. Pacelli F, Rosa F, Marrelli D, et al. Do perioperative blood transfusions influence prognosis of gastric cancer patients? Analysis of 927 patients and interactions with splenectomy. Ann Surg Oncol. 2011;18:1615-23.

Publisher's Note Springer Nature remains neutral with regard to jurisdictional claims in published maps and institutional affiliations. 